\title{
Reaching a Consensus through Participatory Design with Children: The Two-Way Approach
}

\author{
Tuba Uğraş \\ Yildiz Technical University \\ Istanbul, Turkey \\ tubaugras@gmail.com
}

\author{
Kerem Rızvanoğlu \\ Galatasaray University \\ Istanbul, Turkey \\ krizvanoglu@gsu.edu.tr
}

\author{
Sevinç Gülseçen \\ Istanbul University \\ Istanbul, Turkey \\ gulsecen@istanbul.edu.tr
}

\begin{abstract}
In this paper, we present a case study which investigates the process of reaching a consensus in a mobile game design project for children, carried on with the participatory design approach. Making consensus, here, is a matter of making group decision on one of the narrative designs produced in different themes with various techniques throughout the early stage of co-design process. We need a new methodology because neither of the methods in the relevant literature is perfectly fit to our case. Therefore we developed "Two-way design selection technique" that consisted of separate debriefing sessions with children and adults. Results showed that the new technique was successful in terms of children's and adults' effective participation, contribution to the co-design process as well as reaching a consensus. On the other hand, it has some limitations regarding interaction. In this sense, future studies should focus on enabling more interactive discussion opportunities.
\end{abstract}

Participatory design, Co-design, Design selection, Consensus, Game design, Narrative design, Children.

\section{INTRODUCTION}

In Participatory Design, users are actively involved in design process with the intention of making the user an equal partner in the design team (Preece et al., 2002). It's important that participants should reflect their personal insights within the discussion scope and reach a consensus since the design direction is determined by contributions of all the participants.

Children, as users of the technology developed for children, have participated in the design process as well. Druin (1999a) declares four roles of children: user, tester, informant, and design partner. Children in the role of design partner are considered as the equal stakeholders in the design process; in this way, it has the strength of empowering children throughout the process. On the other hand, it has a challenge that team decisions must be negotiated between adults and children.

In this context, this study aimed to generate a new technique, namely the two-way approach in selecting a design in a co-design study with children. Research questions were created as the following:

(i) Do children and adults participate effectively, in terms of sharing ideas with their reasoning?

(ii) Does the new technique contribute to the co-design process, in terms of providing collaboration, engagement, and fun? (iii) Does the new technique enable to reach a consensus?

The importance of this study lies in having the potential of fulfilling the need for such a technique as well as making contributions to empower children as design partners in the design process of technology for children. The study aims to contribute to the field of Child-Computer Interaction (CCl). Besides, other fields, such as education or intelligent environments (IE) design, can also benefit by applying the technique for the co-design studies with children.

\section{BACKGROUND STUDY}

When we focus on making group decisions or making evaluations in the design process with children, we see a number of techniques being used. Big ldeas (Druin, 1999b; Guha et al., 2013; Fails et al., 2013) is used for the purpose of making group decisions in the early stage of design, regarding a single design item. Sticky Notes (Druin, 1999b; Guha et al., 2013; Fails et al., 2013) is used for making group decisions or evaluations in the early or late stage of design, regarding a single design item. Funometer, Smileyometer, Fun Sorter, Again-Again table (Read et al., 2002) and This or That (Zaman \& Abeele, 2007), on the other hand, are used only for making evaluations in the late stage of design in spite of being used for multiple design items. Yet we need a way of making group decisions in the early stage of 
design, regarding the presence of multiple design items. Therefore, we require the proposition of a new original methodology.

\section{METHODOLOGY}

In this paper, we present a case study, which investigates the process of reaching a consensus on the selection of a narrative design in a mobile game design project for children that is carried on with the participatory design approach, in which children are design partners. Making consensus, here, is a matter of making group decision on one of the narrative designs produced in different themes with various techniques throughout the early stages of design process.

The team consisted of three visual art designers, three technologists, one game developer, and eight children of ages 7.5-10.5 (5 girls, 3 boys), in addition to the researchers. Children were selected among those who were in the stage of middle childhood, since Druin et al. (1997) stated that 7-10 year-olds work well as design partners thanks to their verbal and self-reflective abilities. Also, oral consent process of children and parents were followed after informing them about the project. Adults were included in the team, taking into account the professional qualifications required in the process.

\subsection{Two-way design selection technique}

Indeed, it is a good idea for our case to utilize of evaluation methods such as preference testing, combining with a discussion through an interview session with each child.

We adopted Preference Ranking, in that participants are asked for the presentation of three or more samples to rank according to their preference (Hein et al., 2008).

On the other hand, using traditional interview techniques in designing with children has limited success (Dindler \& Iverson, 2007). In order to increase engagement in the interview, we decided to utilize of Sticky Notes by making the modifications of using color-coded sticky notes for the likes and the dislikes and attaching them on the related part of the low-fidelity prototype.

Moreover, the most efficient procedure is to determine preferences indirectly after getting information about their liking for the product in direct ways (Lawless \& Heymann, 1999). In This or That, one of the six questions is an indirect measure of preference (Zaman et al., 2013). Similarly, Again-Again table is consisted of a similar question (Read et al., 2002). In accordance with these, we extended the interview session by adding the questions: (1) Would you like to play if this is a game on the market? (2) Would you like to play it again and again? In other words, we used Yes/No Questions which are a simple method of surveying in CCl (Read \& MacFarlane, 2006). The output of the debriefing sessions with children is the brief of children.

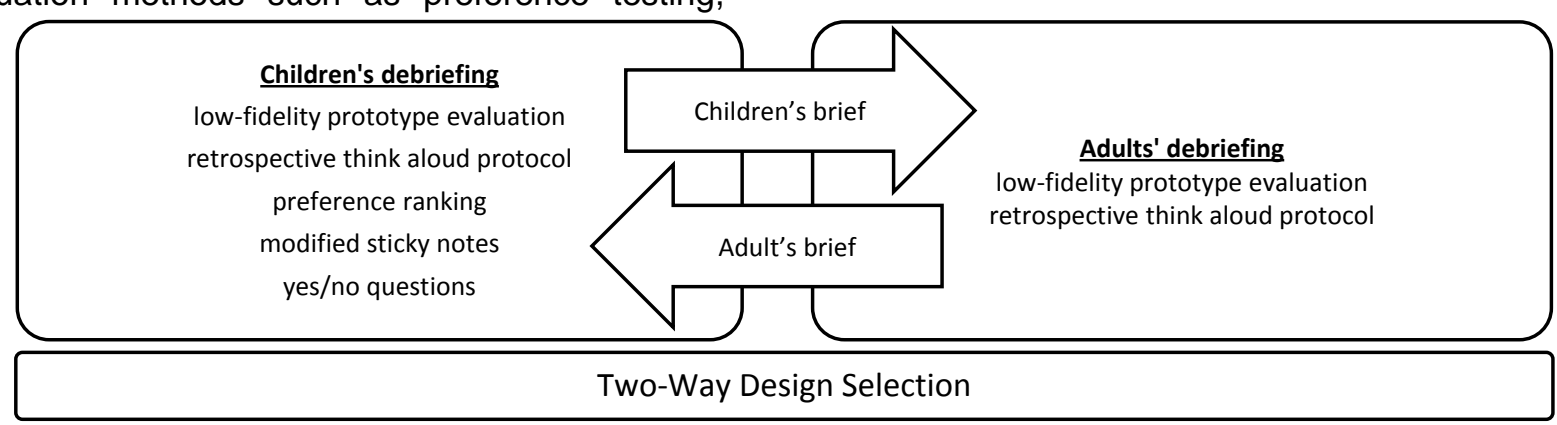

Figure 1: The process of two-way design selection technique.

Considering our intent to reach a consensus of the co-design team, we planned to get the adults involve in the selection process through an in-depth interview. The output of the debriefing session with adults is the brief of adults which is created by taking children's brief into consideration. Unfortunately, for working with children as design partners, it is a challenge that team decisions must be negotiated between children and adults (Druin, 1999a). We tried to minimize that challenge by a short meeting with the participation of both children and adults in order to share adults' brief with children.

\subsection{Process}

Debriefing sessions with children were held by the researchers in a one-on-one interview format. Each session lasted approximately 45 minutes. During each session, the child was asked about what she/he liked or disliked, and the rationale for the likes/dislikes. Retrospective think aloud protocol took place when needed. Sticky notes were used for the child to write down her/his opinions and place them on the related part of the low-fidelity prototype. The child was also asked the Yes/No questions for each of the narrative designs. At the end of each session, the child was asked to rank the narrative designs 
from the most preferred to the least. Magic Perfume (4) and Wolf Man (3) were the narrative designs which were mostly liked by the children.

Table 1: The narrative designs produced throughout the project.

\begin{tabular}{|l|l|l|l|}
\hline \multicolumn{1}{|c|}{ Name } & \multicolumn{1}{|c|}{ Theme } & $\begin{array}{c}\text { Genre } \\
\text { elements }\end{array}$ & $\begin{array}{l}\text { Design } \\
\text { technique } \\
\text { based on }\end{array}$ \\
\hline $\begin{array}{l}\text { Magic } \\
\text { Perfume }\end{array}$ & Trust & Adventure & $\begin{array}{l}\text { narrative } \\
\text { models }\end{array}$ \\
\hline Wolf Man & Power & Combat & $\begin{array}{l}\text { game } \\
\text { elements }\end{array}$ \\
\hline $\begin{array}{l}\text { The Queen } \\
\text { and Soldiers }\end{array}$ & Dominance & $\begin{array}{l}\text { Strategy, } \\
\text { Combat }\end{array}$ & $\begin{array}{l}\text { game } \\
\text { elements }\end{array}$ \\
\hline $\begin{array}{l}\text { Auros \& } \\
\text { Ciko \& Bella }\end{array}$ & Friendship & $\begin{array}{l}\text { Adventure } \\
\text { Combat }\end{array}$ & $\begin{array}{l}\text { game } \\
\text { elements }\end{array}$ \\
\hline
\end{tabular}

In debriefing sessions with adults, low-fidelity prototype evaluation and retrospective think aloud protocol were used. Adults discussed on the narrative designs in the context of feasibility and the definition of game narrative design. At the end of the adult debriefing session, results from the debriefing sessions with children were also shared with the adults and common patterns in the outcomes of both sessions were identified. Among the narrative designs mostly liked by children, the only narrative which was feasible to develop a game and carried the features of a game narrative was the one, Wolf Man.

The selection process concluded with the short meeting of adults and children together, in order for sharing the adults' brief with children. As a result of the two-way design selection process, the narrative design of Wolf Man was chosen by reaching a consensus.

\section{ANALYSIS AND DISCUSSION}

All the sessions with children and adults were recorded by voice recording. One of the researchers also took notes during the sessions. Data, which were collected in different formats such as voice recordings and written notes, were analysed qualitatively according to the analysis framework based on research questions (1) children's and adults' effective participation, (2) contribution to the co-design process (3) reaching a consensus.

Table 2: Research model.

\begin{tabular}{|c|c|c|c|c|}
\hline $\begin{array}{c}\text { Analysis } \\
\text { framework } \\
\text { item }\end{array}$ & $\begin{array}{l}\text { Context of } \\
\text { discussion }\end{array}$ & $\begin{array}{l}\text { Dimensions of } \\
\text { indicators }\end{array}$ & Indicators & Data source \\
\hline \multirow[t]{2}{*}{$\begin{array}{l}\text { Effective } \\
\text { participation }\end{array}$} & \multirow[t]{2}{*}{ Participation } & $\begin{array}{l}\text { children's effective } \\
\text { participation }\end{array}$ & $\begin{array}{l}\text { Children's sharing their opinions as a like } \\
\text { or a dislike with an explanation } \\
\text { Any remarkable behaviour of the child }\end{array}$ & $\begin{array}{l}\text { Modified sticky notes } \\
\text { Yes/No questions } \\
\text { Preference ranking }\end{array}$ \\
\hline & & $\begin{array}{l}\text { adults' effective } \\
\text { participation }\end{array}$ & $\begin{array}{l}\text { Adults' sharing opinions in accordance } \\
\text { with their professional backgrounds }\end{array}$ & $\begin{array}{l}\text { Debriefing session } \\
\text { with adults }\end{array}$ \\
\hline \multirow[t]{3}{*}{$\begin{array}{l}\text { Contribution } \\
\text { to the } \\
\text { process }\end{array}$} & \multirow[t]{2}{*}{ Collaboration } & $\begin{array}{l}\text { child-child } \\
\text { interaction }\end{array}$ & $\begin{array}{l}\text { Any new idea from the child as a } \\
\text { contribution to the narrative } \\
\text { Any response to that kind of contribution } \\
\text { made by another child }\end{array}$ & Modified sticky notes \\
\hline & & $\begin{array}{l}\text { children-adults } \\
\text { interaction }\end{array}$ & Conversation between children and adults & Short meeting \\
\hline & $\begin{array}{l}\text { Fun and } \\
\text { Engagement }\end{array}$ & $\begin{array}{l}\text { fun and/or } \\
\text { engagement }\end{array}$ & $\begin{array}{l}\text { Any reaction of the child to the activities } \\
\text { throughout the session } \\
\text { Gestures and mimics }\end{array}$ & $\begin{array}{l}\text { Modified sticky notes } \\
\text { Yes/No questions } \\
\text { Preference ranking }\end{array}$ \\
\hline \multirow[t]{3}{*}{$\begin{array}{l}\text { Reaching a } \\
\text { consensus }\end{array}$} & \multirow[t]{3}{*}{ Consensus } & brief of children & The preference of the child & $\begin{array}{l}\text { Modified sticky notes } \\
\text { Yes/No questions } \\
\text { Preference ranking }\end{array}$ \\
\hline & & brief of adults & $\begin{array}{l}\text { Feasibility and representativeness of the } \\
\text { game features for each narrative designs }\end{array}$ & $\begin{array}{l}\text { Debriefing session } \\
\text { with adults }\end{array}$ \\
\hline & & $\begin{array}{l}\text { combination of the } \\
\text { briefs }\end{array}$ & $\begin{array}{l}\text { Consistency across the techniques } \\
\text { Consistency across children } \\
\text { Consistency between children and adults }\end{array}$ & $\begin{array}{l}\text { Debriefing session } \\
\text { with adults } \\
\text { Short meeting }\end{array}$ \\
\hline
\end{tabular}

\subsection{Children's and adults' effective participation}

It was observed that the children authentically shared their opinions. Moreover, children, without being asked for, spontaneously explained their opinions with their reasoning, except shy ones. However, shy children performed better in one-onone interviewing than in a group work, although Hanna et al. (1997) stated that shyer children may be uncomfortable in a one-on-one formats. On the other hand, there is a thread of distracting from the purpose of the interview in case of talkative children, who shared too many opinions by talking about unrelated issues or by asking for changing their initial ideas. Fortunately it could be dealt by listening the child for a while in order to keep her/him motivated and then turning back to the process. Adults also shared their opinions, based on their professional background. 


\subsection{Contribution to the co-design process}

In line with the studies of Walsh et al. (2013), Frauenberger et al. (2012) and (Read \& MacFarlane, 2006), our modified sticky notes played the role of engaging children into the debriefing sessions, in terms of providing physical interaction and focusing on the narrative; and the role of making the process fun by allowing the child to use coloured sticky notes and draw something in addition to writing on sticky notes. Moreover, considering the indicators related to enjoyment and engagement such as comments, smiles, frowns, sighs, etc. (Hanna et al., 1997; Macfarlane et al., 2005), it was highly fun and providing engagement for the children to participate in such a debriefing session. There was an exception; it took relatively long time because the children wrote each like and dislike separately and the researcher also took notes while interviewing. Indeed, Read \& MacFarlane (2006) suggested to "keep it short" among their guidelines for surveys with children. One possibility, to minimize the duration, could be modifying sticky note as using just coloured sticky notes without writing on them and putting them on the related area of the prototype.

Considering collaboration in our case, the short meeting enabled children-adults interaction in some degree. On the other hand, there was a challenge in terms of child-child interaction altough we tried to maximize child-child interaction indirectly by providing the opportunity for the child to hear from other children as the researcher quoted from other children during the interviewing. One possibility, to minimize that challenge, could be interviewing with children in pairs by making them come to an agreement, as Hanna et al. (2004) suggested.

\subsection{Reaching a consensus}

The findings indicated that there was a high consistency in children's individual reflections coming from different techniques used throughout the selection process. As in the study of Hanna et al. (2004), children's rationale validated their rankings. Although the children in interviewing tended to say Yes (Breakwell et al., 2004, p.247), it was observed that the children replied the Yes/No questions authentically.

There was also a high consistency across children; as in the study of Hanna et al. (2004). On the other hand, for most of the children, it was not possible to rank the same narrative as the first; as in the study of Hanna et al. (2004). It is not surprizing since children have different priorities (Breakwell et al., 2004, p.247). Unlike the known difference between boys' and girls' interests in battle games (Joiner, 1998; Valkenburg \& Cantor, 2000; Hanna et al., 2004), we found that both boys and girls were interested in such genre. Our finding of a few clear age differences is in line with the study of Hanna et al. (2004).

The findings also indicated that there was relatively consistency between children and adults.

Moreover, modified sticky notes and Yes/No questions provided a cross check opportunity for preference ranking results. In this sense, using more than one technique can be considered as a strength ot the two-way design selection, as $\operatorname{Sim}$ \& Horton (2012) emphasized the need for using more than one method to enhance the reliability.

\section{CONCLUSION}

Results showed that the two-way design selection technique contributed to the consensus process by the implications listed below:

- It provided effective participation of both children and adults. Children could share their opinions with their reasoning thanks to one-on-one interviewing sessions, even in case of shy childs.

- It contributed to the co-design process by providing engagement and fun during the debriefing session, especially through modified sticky notes activity, by allowing children physically active and making them focus on the design. However, it would be better to shorthen the duration by making the modifications discussed above.

- It contributed to the co-design process in terms of collaboration by providing childrenadults interaction through the short meeting. However, there is still a challenge in providing child-child interaction.

- It enabled effectively to reach a consensus for a co-design team consisting of children and adults, since it enabled the use of more than one technique which contributed to the process separately.

In sum, this technique could be useful in the early stage of the co-design process with children, in order for making group decisions when the designs produced in different themes and/or with different techniques, i.e. in case of multiple design items. Although we developed this technique through a mobile game design project, it is possible to adapt it into the co-design process of any kind of technology for children. It is expected that the results of this study present useful insights for researchers and practitioners in the related fields, such as education and IE as well as $\mathrm{CCl}$.

Acknowledgement: The author gratefully acknowledges the PhD grant (\#2211/C) from TÜBITAK (The Scientific and Technological Research Council of Turkey). 


\section{REFERENCES}

Breakwell, G.M., Hammond, S.. and Fife-schaw, C. (2004) Research methods in psychology. Sage Publications.

Dindler, C. and Iversen, O.S. (2007) Fictional inquiry-design collaboration in a shared narrative space. CoDesign, 3(4), pp.213-234.

Druin, A., Boltman, A., Miura, A., Platt, M., Uscher, N. and Knotts-Callahan, D. (1997). Understanding children's technology needs and desires. Intel Research Council Grant Summary.

Druin, A., 1999a. The Role of Children in the Design of New Technology. HCIL Technical Report No. 99-23.

Druin, A. (1999b) May. Cooperative inquiry: developing new technologies for children with children. In Proceedings of the SIGCHI conference on Human Factors in Computing Systems (pp. 592-599). ACM.

Fails, J.A., Guha, M.L. and Druin, A. (2013) Methods and techniques for involving children in the design of new technology for children. Foundations and Trends $\AA$ in Human-Computer Interaction, 6(2), pp.85-166.

Frauenberger, C., Good, J., Alcorn, A. and Pain, H. (2012, June) Supporting the design contributions of children with autism spectrum conditions. In Proceedings of the 11th International Conference on Interaction Design and Children (pp. 134-143). ACM.

Guha, M.L., Druin, A. and Fails, J.A. (2013) Cooperative Inquiry revisited: Reflections of the past and guidelines for the future of intergenerational co-design. International Journal of Child-Computer Interaction, 1(1), pp.14-23.

Hanna, L., Risden, K. and Alexander, K. (1997) Guidelines for usability testing with children. interactions, 4(5), pp.9-14.

Hanna, L., Neapolitan, D. and Risden, K. (2004) June. Evaluating computer game concepts with children. In Proceedings of the 2004 conference on Interaction design and children: building a community (pp. 49-56). ACM.

Hein, K.A., Jaeger, S.R., Carr, B.T. and Delahunty, C.M. (2008) Comparison of five common acceptance and preference methods. Food quality and preference, 19(7), pp.651-661.

Joiner, R.W. (1998) The effect of gender on children's software preferences. Journal of Computer Assisted Learning, 14(3), pp.195-198.

Lawless, H.T. and Heymann, H. (1999) Acceptance and preference testing. In Sensory Evaluation of Food (pp. 430-479). Springer, Boston, MA.
MacFarlane, S., Sim, G. and Horton, M. (2005) June. Assessing usability and fun in educational software. In Proceedings of the 2005 conference on Interaction design and children (pp. 103-109). ACM.

Preece, J., Rogers, Y., \& Sharp, H. (2002) Interaction design: Beyond human-computer interaction, New York: John Wiley \& Sons, Inc.

Read, J.C. and MacFarlane, S. (2006) June. Using the fun toolkit and other survey methods to gather opinions in child computer interaction. In Proceedings of the 2006 conference on Interaction design and children (pp. 81-88). ACM.

Read, J.C., MacFarlane, S.J. and Casey, C. (2002) August. Endurability, engagement and expectations: Measuring children's fun. In Interaction design and children (Vol. 2, pp. 1-23). Shaker Publishing Eindhoven.

Sim, G. and Horton, M. (2012) June. Investigating children's opinions of games: Fun Toolkit vs. This or That. In Proceedings of the 11th International Conference on Interaction Design and Children (pp. 70-77). ACM.

Valkenburg, P.M. and Cantor, J. (2000) Children's likes and dislikes of entertainment programs. In D. Zillmann and P. Vorderer (Eds), Media Entertainment: The Psychology of its Appeal (pp. 135-152). Mahwah, NJ: Lawrence Erlbaum Associates, Inc.

Walsh, G., Foss, E., Yip, J. and Druin, A. (2013) April. FACIT PD: a framework for analysis and creation of intergenerational techniques for participatory design. In Proceedings of the SIGCHI Conference on Human Factors in Computing Systems (pp. 2893-2902). ACM.

Zaman, B. and Abeele, V. (2007) January. How to measure the likeability of tangible interaction with preschoolers. In CHI Nederland (pp. 57-59). Infotec Nederland.

Zaman, B., Abeele, V.V. and De Grooff, D. (2013) Measuring product liking in preschool children: An evaluation of the Smileyometer and This or That methods. International Journal of ChildComputer Interaction, 1(2), pp.61-70. 